\title{
Bazı Tanenlerin Soğan (Allium cepa L.) Dip Çürüklüğü Hastalık Etmeni Fusarium oxysporum f.sp. cepae Üzerine Antifungal Etkisi
}

\author{
İdris BEKTAŞ ${ }^{1}$, Ceyda ÜCÜK², Mustafa KÜSEK ${ }^{3}$ \\ ${ }^{1}$ Amasya Üniversitesi, Suluova Meslek Yüksekokulu, Bitkisel ve Hayvansal Üretim Bölümü, Amasya, ${ }^{2,3}$ Kahramanmaraş Sütçü İmam \\ Üniversitesi, Ziraat Fakültesi, Bitki Koruma Bölümü, Kahramanmaraş \\ ${ }^{1}$ https://orcid.org/0000-0001-7409-4837, ${ }^{2}$ https://orcid.org/0000-0002-9695-281X, ${ }^{3 h t t p s: / / o r c i d . o r g / 0000-0002-6320-5869 ~}$ \\ $\varangle$ : idris.bektas@amasya.edu.tr
}

\section{ÖZET}

Fusarium oxysporum f.sp. cepae (FOC)'nın neden olduğu dip çürüklüğü hastalığı önemli derecede ürün kayıplarına neden olmaktadır. Bu çalışmada 3 farklı ticari tanen ekstraktının(Artutan $\mathrm{K}$, Artutan ve Farmatan) farklı dozları $(\% 0.25,0.5,1.0,2.0$, ve 4.0) ve ticari bir fungusit olan Antracol WP 70'in (\%0.05) FOC misel gelişimi üzerine etkisi in vitro ortamda incelenmiştir. Elde edilen sonuçlara göre; Artutan ve Farmatan uygulamaları fungal misel gelişimini $\% 57,3$ ile $\% 51,4$ oranında engellemiştir. Aynı konsantrasyondaki Artutan \%57,3; Farmatan ise \%51,4 oranında misel gelişimini engellemiştir. Ayrıca tüm tanen ekstraktlarının \%2 ve \%4'lük konsantrasyonu ve Artutan K'nın \% 1'lik konsantrasyonu FOC misel gelişimini Antracol WP 70 den daha daha fazla baskılamıştır $(p<0.05)$. Üç farklı tanen ekstraktının farklı konsantrasyonları FOC'un in vitro ortamda misel gelişimine etkisi negatif kontrol ile karşılaştırıldığında birçok konsantrasyonunun antifungal özellik gösterdiği belirlenmiştir. Sonuç olarak; yapılan bu çalışmada kullanılan tanenler bitki hastalık etmenlerine karşı kullanılan sentetik bileşiklere alternatif olarak kullanılabileceği saptanmiştır.

Antifungal Effect of Some Tannins on Fusarium oxysporum f. sp. cepae the Agent of Onion (Allium cepa L.) Root Rot Disease

\section{ABSTRACT}

The Fusarium oxysporum f.sp. cepae (FOC) is one of the most important agents causing significant crop losses. In this study, different doses $(0,0.25,0.5,1.0,2.0$ and $4.0 \%)$ of three different commercial tannin extracts (Artutan K, Artutan and Farmatan) and one dose $(0.05 \%)$ of a commercial fungicide (Antracol WP 70 ) were investigated, on FOC mycellium growth in vitro conditions. Results indicated that Artutan with $\mathrm{K} 4 \%$ concentration inhibited FOC mycellium growth at the highest rate of $76.4 \%$ compared to negative control. At the same concentration, Artutan and Farmatan inhibited FOC mycelial growth by $57.3 \%$ and $51.4 \%$, respectively. In addition, $2 \%$ and $4 \%$ concentration of all tannin extracts and $1 \%$ concentration of Artutan K suppressed FOC mycellium growth more than Antracol WP $70(p<0.05)$. Most of concentration was found to have antifungal effect, when different concentrations of three different tannin extracts were compared to negative control. We can conclude from this study that tannins can be used as an alternative to synthetic compounds in plant disease agents management.
Araştırma Makalesi

$\begin{array}{ll}\text { Makale Tarihçesi } \\ \text { Geliş Tarihi } & : 25.06 .2019 \\ \text { Kabul Tarihi } & : 07.10 .2019\end{array}$

Anahtar Kelimeler

Tanen

Fusarium oxysporum f.sp. cepae

Antifungal aktivite

\section{Research Article}

$\begin{array}{ll}\text { Article History } & \\ \text { Received } & : 25.06 .2019 \\ \text { Accepted } & : 07.10 .2019\end{array}$

Keywords

Tannin

Fusarium oxysporum f.sp. cepae

Antifungal activity

To Cite : Bektaş İ, Ücük C, Küsek M 2020. Bazı Tanenlerin Soğan (Allium cepa L.) Dip Çürüklüğü Hastalık Etmeni Fusarium oxysporum f.sp. cepae Üzerine Antifungal Etkisi. KSÜ Tarım ve Doğa Derg 23 (1): 1-6. DOI: 10.18016/ksutarimdoga.vi.582007.

\section{GİRIŞ}

Soğan (Allium cepa L. ) dünyanın bir çok yerinde tarımı yapılan önemli bir kültür bitkisidir. Dünya 
milyon 120 bin 581 ton üretimi ile dünya sıralamasında beşinci sırada bulunmaktadır (FAO, 2018). TÜİK verilerine göre, 2017 yılında kuru soğan üretimi yapılan önemli iller değerlendirildiğinde 460.012 ton ile Ankara birinci olup, bu ili sırası ile 293.551 ton ile Amasya, 229.931 ton ile Hatay, 219.904 ton ile Adana, 174.919 ton ile Çorum, 156.105 ton ile Eskişehir, 133.571 ton ile Tokat, 85.414 bin ton ile Bursa illerimiz izlemektedir (TÜIK, 2018). Bu tarım alanlarında birçok hastalık etmeni bulunmaktadır. $\mathrm{Bu}$ hastalık etmenlerinden en önemlisi olan Fusarium oxysporum f.sp. cepae (FOC)'nın neden olduğu dip çürüklüğü hastalığı en önemli hastalık olarak kabul edilmektedir (Javaid ve ark., 2017). Çin, Türkiye, İtalya, Japonya, Güney Afrika ve ABD başta olmak üzere soğan üretimi yapılan hemen hemen her ülkede görülen hastalık \% 60-80'lere kadar verim kayıplarına neden olmaktadır (Özer ve Köycü, 2004). Çimlenme sonrası genç fidelerin ölümüne sebebiyet veren fungus, soğan oluşturmuş gelişmiş bitkilerde kök kısmında çürüklük oluşturmakta ve bu nedenle hastalığa dip çürüklüğü adı verilmektedir (Cramer, 2000). Hastalık etmeni, bir çeşit fungusit olan Carbendazim ve Antracol ile yapilan tohum muameleleri ile kontrol altına alınabilmektedir (Behrani ve ark., 2015). Son yıllarda kimyasalların çevre ve sağlığa olumsuz etkileri ve bitki patojenlerinin kimyasallara karşı dayanıklılık oluşturmaları gibi nedenlerden dolayı kimyasal mücadeleye alternatif yeni mücadele yöntemleri araştırılmıştır (Gupta ve ark., 1987; Mimbs IV ve ark., 2016). Toprak bakterileri ile yapılan biyolojik mücadele ve antimikrobiyal etki gösteren bazı bitki ekstraktlarının kullanımı farklı bitki patojenlerine karşı kimyasal mücadelenin potansiyel bir alternatifidir (Soylu ve ark., 2005; Soylu ve ark., 2010). Bitkilerin sekonder bileşiklerinden olan polifenollerin, tanenlerin ve flavonoidlerin antimikrobiyal aktiviteye sahip oldukları belirlenmiştir (Ahmad ve Beg, 2001; Machado ve ark., 2003; Naz ve ark., 2007; Shan ve ark., 2007). Bunlar arasındaki en önemli sekonder bileşik olan tanenlerin fungal, maya, bakteri ve bazı virüs hastalık etmenleri üzerine önemli düzeyde antimikrobiyal etkileri bulunmaktadır (Yang ve ark, 2000; Akiyama ve ark., 2001; Lu ve ark, 2004; Hao ve ark., 2012). Bileşikler polifenolik olup, kolza, bakla, çay ve sorgum gibi bitkilerden elde edilen, açık sarıkahverengi toz, pul ya da süngerimsi bir kütle halindeki biçimsiz (amorf) bileşiklerdir. Tanenler genellikle bitkilerin kök, odun, kabuk, yaprak ve meyvelerinde bulunup özellikle hasat edilmeden önce meyvelerde meydana gelebilecek mikrobiyal enfeksiyonlara karsı doğal bir savunma mekanizması oluştururlar (Scalbert, 1991). Yapılan bu çalışmada Meşe (Quercus ithaburensis ssp. macrolepi)'den Artutan, kızılçam(Pinus brutia)' dan Artutan K ve kestane ağacın (Castanea sativa Mill.)'dan Farmatan grubuna dahil izole edilen ticari tanenler kullanılmıştır. Tanenlerin PDA besi ortamında farklı dozları hazırlanarak in vitro ortamda bitki patojeni FOC'un misel gelişimine etkisi incelenmiştir. Elde edilen sonuçlar kendi aralarında ve ticari bir fungusit olan Antracol WP 70 etkisi ile istatistiki olarak karşılaştırılmıştır.

\section{MATERYAL ve METOD}

\section{Fungal Patojen FOC}

Soğan dip çürüklüğü etmeni olan FOC Amasya Üniversitesi Suluova Meslek Yüksekokulu Bitki Koruma Laboratuvarından temin edilmiştir. Yapılan daha önceki çalışmalarda doğal olarak enfekte olan soğanların dip kısmından izole edilen FOC'un tanılanması moleküler ve morfolojik özelliklere göre yapılmıştır (Bektas ve Kusek, 2019). FOC'un geliştirilmesinde ise Patates Dextroz Agar (PDA) besi ortamı kullanılmıştır.

\section{Tanenlerin elde edilmesi ve çözeltilerinin Hazırlanması}

Çalışmada Plamuttan (Quercusithaburensis ssp. macrolepis) izole edilmiş Artutan, kızılçamdan (Pinus brutia) izole edilmiş Artutan $\mathrm{K}$ ve Kestane (Castanea sativa Mill) ağacından izole edilmiş Farmatan ticari tanenleri kullanılmıştır. Ticari olarak temin edilen taneneler son konsantrasyonu \% $0.25,0.5,1.0,2.0$ ve 4.0 olacak şekilde Boonsang ve ark. (2014) göre PDA besi ortamına karıştırılarak yapılmıştır. Pozitif kontrol amaçlı olarak soğan dip çürüklüğü hastalığına karşı kullanılan ticari bir fungusit olan Antracol WP 70 firmanın önerdiği doz olan \%0.05 oranında hazırlanmıştır. Negeatif konrolde ise PDA içerisine herhangi bir madde eklemesi yapılmamıştır. Bu şekilde hazırlanan tüm besi oramları $121^{\circ} \mathrm{C}^{\prime}$ de 15 dak. otoklav yapılmıştır.

\section{Tanenlerin FOC'un misel gelişimi üzerine etkisi}

Farklı dozdaki tanenlerin ve Antracol WP 70'in FOC misel gelişimi üzerine etkisi belirlemek için petrilere dökülen ve katılaşmış PDA besi ortamının merkezi bir haftalık FOC kültüründen alınan $10 \mathrm{~mm}$ çapındaki kültürler yerleştirilmiştir. Deneme üç tekrarlı bir şekilde yapılmıştır. Ekim yapılan besi ortamları inkübatörde $27 \pm 1^{\circ} \mathrm{C}$ inkübe edilmiştir. Besi ortamlarında gelişen fungus çapları 7 gün sonra ölçülerek tanenlerin gelişime etkisi aşağıdaki formule göre hesaplanmıştır (Deans ve Svoboda, 1990).

Misel Gelişim Engelleme \%= $[(A-B) / A]_{x} 100$

A: Uygulama yapılmamış kontrol petrisindeki fungal misel çapı

B: Uygulama yapılmış petrilerindeki fungal miselçapı

\section{Istatistiki Analiz}

Farklı dozların ve pozitif kontrolün negetif kontrole göre FOC misel gelişimine etkisi belirlenmiştir. 
Uygulamalarda ölçülen fungus çapları kendi aralarinda ve kontrol uygulamalar ile karşılaştırılmasında SPSS 20 programı kullanılarak Duncan çoklu karşılaştırma testi ile yapılmıştır $(\mathrm{p}<0.05)$.

\section{BULGULAR ve TARTIŞMA}

In vitro ortamda yapılan çalışmada 3 farklı ticari tanen ekstraktının (Farmatan, Artutan ve Artutan K) 5 farkl konsantrasyonunun $(\% 0.25,0.5,1.0,2.0$ ve 4.0) FOC izolatının misel gelişimine etkisi belirlenmiştir (Şekil 1).

In vitro ortamda yapılan çalışmada Artutan K \% 4.0 konsantrasyonu FOC misel gelişimini negatif kontrole göre \%76.4 ile en yüksek oranda engellediği saptanmıştır. Aynı konsantrasyondaki Artutan \% 57.3; Farmatan ise \%51.4 oranında misel gelişimini engellemiştir(Çizelge 1).

Yapılan değerlendirmede aynı dozdaki tanenlerin misel gelişimine etkisi istatisiki olarak önemli bulunmuştur $(\mathrm{p}<0.05)$. Artutan K'nın $\% 2.0$ ve $\% 4.0$ konsantrasyonlardaki FOC'un misel gelişimine etkisi istatistiki olarak en etkili doz olarak belirlenmiştir $(\mathrm{p}<0.05)$.

Artutan ve Farmatan tanenlerinin $\% 2$ ve $\% 4$ 'lük konsantrasyonları arasında istatistiki olarak önemli bir fark bulunamamıştır. Tanenlerin misel gelişimin etkisi ticari bir fungusit olan Antracol WP 70 ile karşılaştırılmıştır. Tüm tanenlerin $\% 2$ ve $\% 4$ lük konsatrasyonu ve Artutan K'nın \%1'lik konsantrasyonu FOC misel gelişimine etkisi Antracol WP 70 den daha ekili bulunmuştur $(\mathrm{p}<0.05)$ (Çizelge 1).

Çizelge 1. In vitro ortamda farklı konsantrasyondaki tanenlerin FOC misel gelişimine etkisi

Table 1. Effect of different concentrations of tannins on FOC mycelium growth at the in vitro conditions

\begin{tabular}{|c|c|c|c|}
\hline $\begin{array}{l}\text { Uygulamalar } \\
\text { Treatment }\end{array}$ & $\begin{array}{l}\text { Konsantrasyon(\%) } \\
\text { Concentration (\%) }\end{array}$ & $\begin{array}{c}\text { Fungus çapı } \\
\text { Fungus diameter }(\mathrm{cm}) \pm \mathrm{SS}\end{array}$ & $\begin{array}{c}\text { Yüzde Etki } \\
\text { Percentage impact }\end{array}$ \\
\hline $\mathrm{K}(-)$ & 0 & $6.8 \pm 0,1 \mathrm{~h}$ & - \\
\hline K(+) (Antracol WP 70) & 0.05 & $4.7 \pm 0.6 \mathrm{~d}$ & 30.8 \\
\hline \multirow{5}{*}{ Artutan } & 0.25 & $7.3 \pm 0,1 \mathrm{j}$ & +5.9 \\
\hline & 0.5 & $7.2 \pm 0,2 \mathrm{j}$ & +5.8 \\
\hline & 1 & $6.1 \pm 0.1 \mathrm{f}$ & 10.2 \\
\hline & 2 & $4.2 \pm 0.1 \mathrm{c}$ & 38.2 \\
\hline & 4 & $2.9 \pm 0.1 b$ & 57.3 \\
\hline \multirow{5}{*}{ Artutan K } & 0.25 & $6.9 \pm 0,4 \mathrm{hj}$ & +1.4 \\
\hline & 0.5 & $5.6 \pm 0.0 \mathrm{e}$ & 17.6 \\
\hline & 1 & $3.1 \pm 0.1 \mathrm{~b}$ & 54.4 \\
\hline & 2 & $1.9 \pm 0.0 \mathrm{a}$ & 72 \\
\hline & 4 & $1.6 \pm 0.1 \mathrm{a}$ & 76.4 \\
\hline \multirow{5}{*}{ Farmatan } & 0.25 & $6.9 \pm 0.1 \mathrm{hj}$ & +1.4 \\
\hline & 0.5 & $6.6 \pm 0.1 \mathrm{gh}$ & 2.9 \\
\hline & 1 & $6.3 \pm 0.1 \mathrm{fg}$ & 7.3 \\
\hline & 2 & $4.1 \pm 0.1 \mathrm{c}$ & 39.7 \\
\hline & 4 & $3.3 \pm 0.1 b$ & 51.4 \\
\hline
\end{tabular}

Deneme üç tekrarlı bir şekilde yapılmıştır.Duncan çoklu karşılaştırma testine göre ortalama değerlerin yanındaki aynı harf ile belirtilen değerler arasında istatistiki olarak fark yoktur $(\mathrm{p}<0.05)$. (SS:Standart sapma)

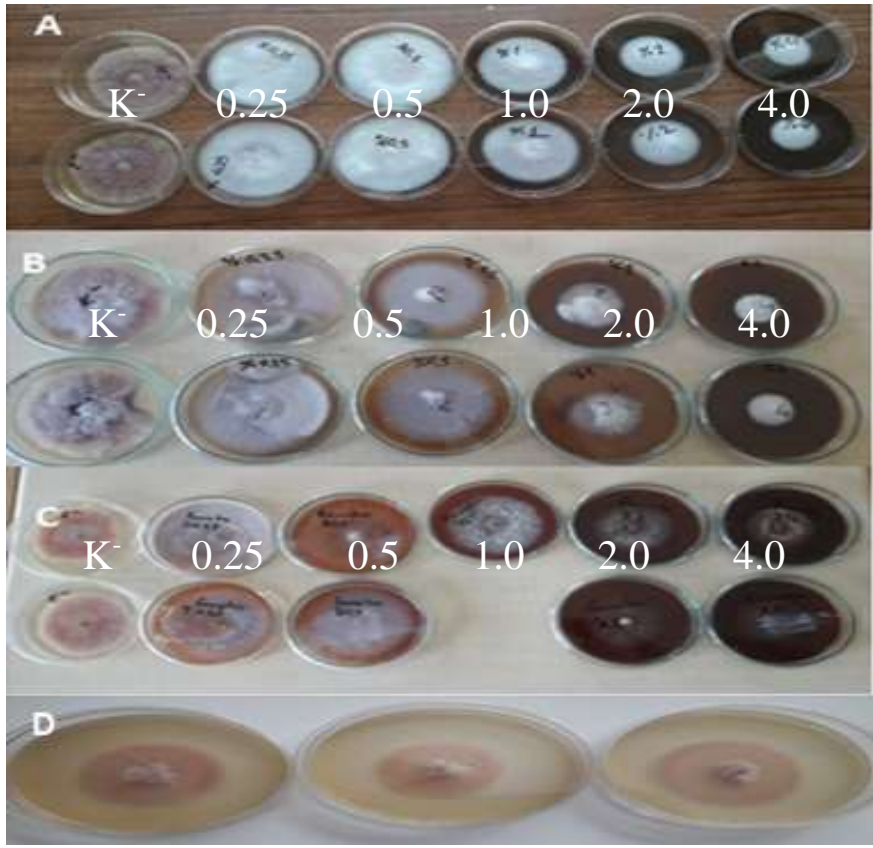

Şekil 1. Tanenlerin (A: Artutan; B: Artutan K; C: Farmatan) farklı \% konsantrasyoriarının ve ticari fungusit ( $\mathrm{D}$ :Antracol $\mathrm{WP}$ 70) in vitro ortamda FOC 'un misel gelişimine etkisi

Figure 1. The effect of different $\%$ concentrations of tannins (A: Artutan; B: Artutan $K$; C: Farmatan) and commercial fungicide ( $D$ : Antracol WP 70) on mycelium growth of FOC at the in vitro conditions 
Tüm tanen ekstraktlarının \%0.25 dozu ve buna ek olarak Artutan \%0.5'lik dozu FOC gelişiminde negatif kontrole göre artış sağladığı görülmüştür. Artutan K ve Farmatan uygulamalarındaki artış negatif kontrole göre istatistiki olarak önemli olmaz iken Artutan uygulamasındaki artış istatistiki olarak önemli olduğu görülmüştür $(\mathrm{p}<0.05)$ (Çizelge 1). Üç farklı tanen ekstraktın farklı konsantrasyonları FOC'un in vitro ortamda misel gelişimine etkisi negatif kontrol ile karşılaştırıldığında bir çok konsantrasyonunun antifungal özellik gösterdiği belirlenmiştir(Şekil 2).

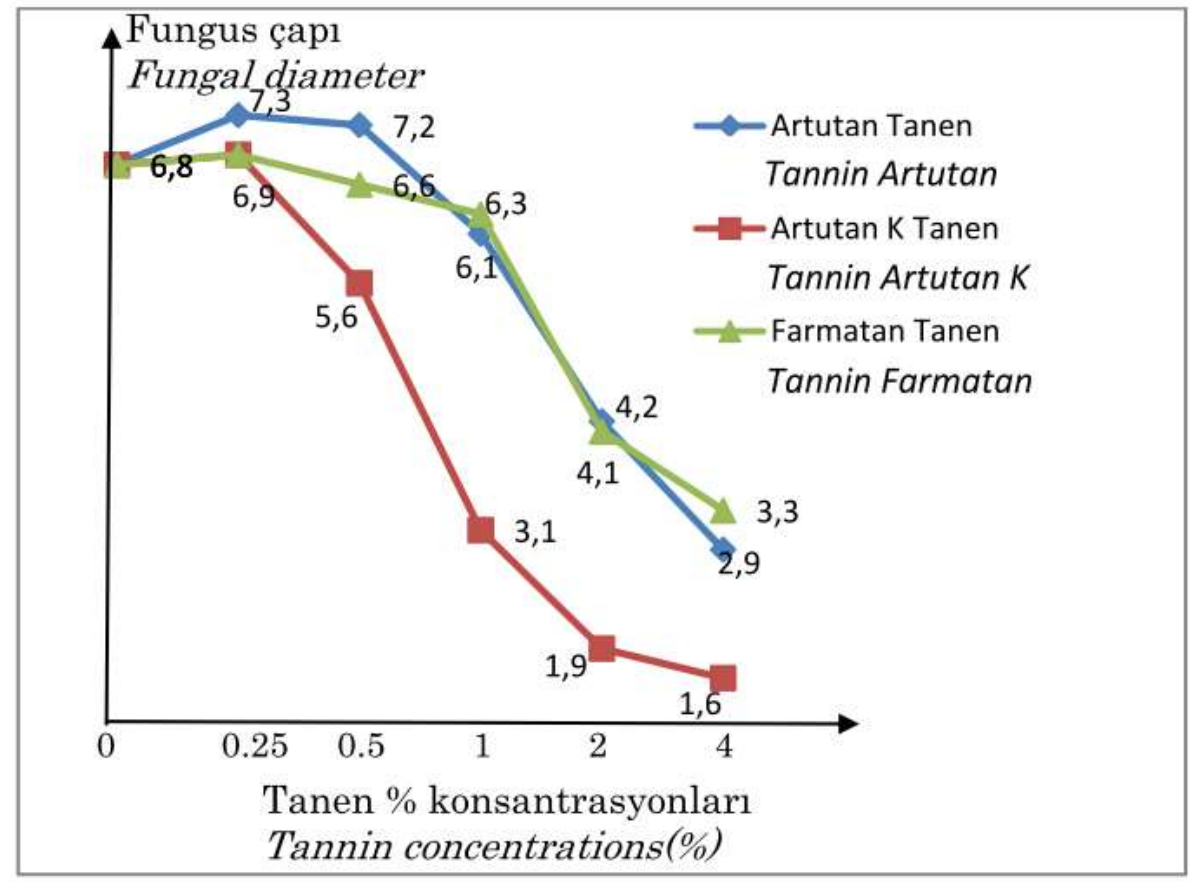

Şekil 2. Tanenlerin(Artutan, Artutan K ve Farmatan) doza bağll olarak in vitro ortamda FOC fungus gelişimine etkisi Figure 2. The effect of tannins (Artutan, Artutan Kand Farmatan) on FOC mycelium growth

Bitkilerden elde edilen eksraktların farklı fungal patojenlere karşı etkili oldugu yapılan çalışmalar ile saptanmıştır. Espacito ve ark. (2019), Castanea sativa yapraklarının metanol ile muamelesinden elde edilen bitki ekstraktlarının bitki patojeni fungus olan Alternaria alternata, Fusarium solani ve Botrytis cinerea'nın misel büyümesini ve spor oluşturmasını engellediği tespit etmişlerdir. Tanenlerin bitki hastalık etmenleri olan funguslara karşı etkinliği in vivo çalışalar ile araştırılmıştır. Zhu ve ark.(2019), yaptıkları çalışmada tanenlerin bitki patojeni Penicillium digitatum kontrolünde alternatif olarak kullanılabileceğini belirtmişlerdir. Tanenlerin antifungal özelliğe sahip oldugunu belirten çalışmada Latte ve Kolodziej (2000), bazı küf ve mayalara karşı benzer şekilde çözünebilir tanenlerin antifungal etki gösterdiklerini tespit etmişlerdir. Artutan K taneni diğerlerine göre düşük dozda (\% 2) da etkili olarak bulunmuş ve \% 4 konsatrasyonda koloni gelişiminin $\%$ 76,4 oranında engellemiştir. Tanenlerin etkileri arasındaki fark içerdikleri bileşiklerin farklı olmasından kaynaklandığı düşünülmektedir. Sibi ve ark. (2012), Muntingia calabura'nın sulu ve matanol ekstraktlarının antibakteriyel ve antifungal etki gösterdiği ve özellikle Fusarium spp. ve Penicillium spp.' ye karşı antifungal etkinin ekstraktların tanen içeriğinden kaynaklandığını bildirmişlerdir.
Tanenlerin antifungal aktiviteye sahip olduğu bilinmesine rağmen, tanen yapısının tesiri üzerindeki etkisi sistematik olarak araştırılmamıştır (Scalbert, 1991). Rabe ve ark. (1997), yaptıkları çalışmada tanen ekstraktları arasındaki antimikrobiyal aktivitenin farklılığı içindeki bileşenlerin değişkenliği ile ilişkili olduğunu bildirmiştir. Castillo ve ark. (2010), yaptıkları çalışmada patojen bir fungus olan Rhizoctania solani 'ye karşı tanenlerin antifungal etksinin elde edilen bitki ekstraktlarına ve çözücü olarak kullanılan organik bileşiklere göre farklı engelleme gösterdiği belirtilmiştir. Alternatif organik çözücünün kullanılması, bitki ekstraktının, $R$. solani'ye karşı yüksek antifungal aktiviteye sahip olmasını, spesifik olarak, sudan daha yüksek miktarlarda polifenolik bileşiklerin çıkarılmasına izin verilen lanolin ve kakao yağının kullanılmasını sağlamıştır. Yılmaz ve ark. (2014), bitki ekstraktlarının biyopestisit olarak kullanılabilmesi için ekstraktların içeriklerinin iyi bilinmesi ve aralarındaki farklılıkların karşılaştırılması gerektiğini belirtmiştir. Al-Zoreky (2009), gıda kaynaklı Saccharomyces cerevisae ve Aspergillus niger'e karşı Punica granatum kabuklarından elde edilen tanen ekstraktının etkisini belirlemiştir. Yapılan bu çalışmada elde ettiğimiz sonuçlar, literatürde yapılan başka çalışma sonuçları ile 
karşılaştırıldığında sonuçların birbirlerini destekler nitelikte olduğu görülmüştür.

\section{SONUÇ ve ÖNERİLER}

Yapılan bu çalışma ile soğanda dip çürüklüğü etmeni olan Fusarium oxysporum f.sp. cepae 'nin mücadelesinde bitkilerden elde edilen tanenlerin kullanım potansiyeline sahip olduğu tespit edilmiştir. Farklı bitkilerden elde edilen bitki tanen ekstraktlarının bitki patojeni fungusa karşı antifungal etkiliğinin doza bağlı olarak varlığ yapılan çalışmada belirlenmiştir. Yapılan çalışma uygulamaya aktarılabilecek yeni alternatif antifungal maddelerin belirlenmesine yönelik bir çalışma olduğu, bitkilerin bünyelerinde bulunan antifungal maddelerin belirlenmesine yönelik çalışmalara yön verebileceği aynı zamanda bu tanen ekstraktlarının bitki hastalık etmenlerine karşı kullanılan sentetik bileşiklere alternatif bileşikler olarak belirlenmesi açısından önemli sonuçlara varılmıştır. Yapılacak olan başka bir çalışmada tanen ekstraktlarının tarla koşullarında etkinliğinin belirlenerek farklı hastalık etmenlerine karşı mücadelede kullanılabilirliğinin ve bitki gelişimine etkisinin araştırılması gerekmektedir.

\section{Çıkar Çatışması Beyanı}

Makale yazarları aralarında herhangi bir çıkar çatışması olmadığını beyan ederler.

\section{Araştırmacıların Katkı Oranı Beyan Özeti}

Yazarlar makaleye eşit oranda katkı sağlamış olduklarını beyan ederler.

\section{KAYNAKÇA}

Ahmad I, Beg AZ 2001. Antimicrobial and Phytochemical Studies on 45 Indian Medicinal Plants Against Multi-Drugand Resistant Human Pathogens. Journal of Ethnopharmacology, 74(2): 113-123.

Akiyama H, Kazuyasu F, Yamasaki O, Oono T, Iwatsuki K 2001. Antibacterial Action of Several Tannins Against Staphylococcus aureus. Journal of Antimicrobial Chemotherapy, 48 (48): 487-491.

Al-Zoreky NS 2009. Antimicrobial Activity of Pomegranate (Punica granatum L.) Fruit Peels. International Journal of Food Microbiology, 134(3): 244-248.

Behrani G, Syed R, Abro M, Jiskani M, Khanzada M 2015. Pathogenicity and Chemical Control of Basal Rot of Onion Caused by Fusarium oxysporum f. sp. cepae. Pakistan Journal of Agriculture, Agricultural Engineering and Veterinary Sciences, 31(1): 60-70.

Bektas I, Kusek M 2019. Phylogenetıc and Morphological Characterization of Fusarium oxysporum f. sp. cepae the Causal Agent of Basal Rot on Onıon Isolated from Turkey. Fresenıus
Environmental Bulletın, 28(3): 1733-1742.

Boonsang N, Dethoup T, Singburaudom N, Gomes NGM, Kijjoa A 2014. In vitro Antifungal Activity Screening of Crude Extracts of Soil Fungi against Plant Pathogenic Fungi. Journal of Biopesticides, 7(2): 156.

Castillo F, Hernándeza D, Gallegosa G, Mendezb M, Rodríguez R, Reyes A, Aguilar

CN 2010. In vitro Antifungal Activity of Plant Extracts Obtained with Alternative Organic Solvent Against Rhizoctonia solani. Industrial Crops and Products, 32(3): 324-328.

Cramer, C.S., 2000. Breeding and Genetics of Fusarium Basal Rot Resistance in Onion. Euphytica, 115(3):159-166.

Deans SG, Svoboda KP 1990. The Antimicrobial Properties of Marjoram (Origanum majorana L.) Volatile Oil. Flavour and Fragrance Journal, 5(3): 187-190.

Esposito T, Celano R, Pane C Piccinelli AL, Sansone F, Picerno P, Zaccardelli M, Aquino RP, Mencherini T 2019. Chestnut (Castanea sativa Miller.) Burs Extracts and Functional Compounds: UHPLC-UV-HRMS Profiling, Antioxidant Activity, and Inhibitory Effects on Phytopathogenic Fungi. Molecules, 24 (302):1-22.

FAO 2018. Faostat. http://www.fao.org/faostat/ en/\#data/QC. (Erişim Tarihi: 13.05.2019).

Gupta R, Srivastava K, Pandey U 1991. Management of Onion Diseases and Insect Pests in India. Onion Newsletter for the Tropics, (3):15-17.

Hao JJ, Liu H, Donis-Gonzalez IR., Lu, XH, Jones AD, Fulbright DW 2012. Antimicrobial Activity of Chestnut Extracts for Potential use in Managing Soil Borne Plant Pathogens. Plant Disease, 96(3): 354-360.

Javaid A, Niaz L, Shoaib A 2017. Effect of Incorporation of Leaf Biomass of Coronopus didymus on Management of Basal Rot Disease of Onion and its Physiology. International Journal of Agriculture and Biology, 19(3):445-452.

Latté KP, Kolodziej H 2000. Antifungal Effects of Hydrolysable Tannins and Related Compounds on Dermatophytes, Mould Fungi and Yeasts. Zeitschrift für Naturforschung C, 55(5-6): 467-472.

Lu L, Liu SW, Jiang SB, Wu SG 2004. Tannin Inhibits HIV-1 Entry by Targeting gp41. Acta Pharmacologica Sinica, 25(2):213-218.

Machado TB, Pinto AV, Pinto MCFR, Leal ICR, Silva MG, Amaral ACF, Netto-dosSantos KR 2003. In vitro Activity of Brazilian Medicinal Plants, Naturally Occurring Naphthoquinones and their Analogues, Against Methicillin-resistant Staphylococcus aureus. International Journal of Antimicrobial Agents, 21(3): 279-284.

Mimbs IV, WH, Cusaac JPW, Smith LM, McMurry ST, Belden JB 2016. Occurrence of Current-Use Fungicides and Bifenthrin in Rain Water Basin 
Wetlands. Chemosphere 159: 275-281.

Naz S, Siddiqi R, Ahmad S, Rasool S, Sayeed S 2007. Antibacterial Activity Directed Isolation of Compounds from Punica granatum. Journal of Food Sciences 72(9): M341-M345.

Özer N, Köycü ND 2004. Seed-Borne Fungal Diseases of Onion, and their Control. In Fruit and Vegetable Diseases (pp. 281-306). Springer, Dordrecht.

Rabe T, Staden J 1997. Antibacterial Activity of South African Plants Used for Medicinal Purposes. Journal of Ethnopharmacology, 56(1): 81-87.

Scalbert A 1991. Antimicrobial Properties of Tannins. Phytochemistry,30(12): 3875-3883.

Shan B, Cai YZ, Brooks J, Corke H 2007. The In Vitro Antibacterial Activity of Dietary Species and Medicinal Herb Extracts. International Journal of Food Microbiology, 117(1): 112-119.

Sibi G, Naveen R, Dhananjaya K, Ravikumar KR, Mallesha M 2012. Potential use of Muntingia calabura L. Extracts Against Human and Plant Pathogens. Pharmacognosy Journal, 4 (34): 44-47.

Soylu S, Soylu EM, Kurt Ş, Ekici ÖK 2005. Antagonistic Potentials of Rhizosphere-Associated Bacterial Isolates against Soil-Borne Diseases of
Tomato and Pepper Caused by Sclerotinia sclerotiorum and Rhizoctonia solani. Pakistan Journal of Biological Sciences 8: 43-48.

Soylu EM, Kurt Ş, Soylu S 2010. In vitro and In Vivo Antifungal Activities of the Essential Oils of Various Plants Against Tomato Grey Mould Disease Agent Botrytis cinerea. International Journal of Food Microbiology, 143(3): 183-189.

TÜIK 2018. Bitkisel Üretim Denge Tabloları 2017/2018. Www.tüik.gov.tr Wrişim tarihi:17.09.2018).

Yang CL, Yen KY 2000. Induction of Apoptosis by Hydrolyzable Tannins from Eugenia jambos L. on Human Leukemia Cells. Cancer Letters, 157(1): 65-75.

Yılmaz M, Kavak S, Baysal Ö 2014. Bazı Ticari Sabit ve Uçucu Yağların Domates Bakteriyel Kanser ve Solgunluk Etmeni Üzerine Antibakteriyel Etkileri. Derim, 31 (1):50-60.

Zhu C, Lei M, Andargie M, Zeng J, Li J 2019. Antifungal Activity and Mechanism of Action of Tannic Acid Against Penicillium digitatum. Physiological and Molecular Plant Pathology, 107: 46-50. 